\title{
Synaptic Changes at the Spinal Cord Level and Peripheral Nerve Regeneration During the Course of Muscular Dystrophy in MDX Mice
}

\author{
Gustavo Ferreira Simões and Alexandre Leite Rodrigues de Oliveira \\ University of Campinas (UNICAMP),
}

Brasil

\section{Introduction}

Muscular dystrophies are part of a group of degenerative diseases of the muscular system, which are characterized by muscle degeneration and structural changes at the neuromuscular junction. The most common form is Duchenne Muscular Dystrophy (DMD) (Whitehead et al., 2006), which affects approximately 1 in every 3500 live births (Balaban et al., 2005; Judge et al., 2005; Withehead et al., 2006; Radley et al., 2007). It is a severe X-linked recessive disorder, where the $X$ chromosome is mutated in the region of the gene $X \mathrm{p} 21$, which encodes for the production of dystrophin (Pearce, 2005).

Dystrophin is a protein located adjacent to the sarcolemma of myocytes (Arahata et al., 1988; Chelly et al., 1988; Carretta et al., 2001). The dystrophin-glycoprotein complex has the functions of maintaining links between the cytoskeleton and the extracellular matrix (Figure 1), maintaining the integrity of the sarcoplasmic membrane, distributing the lateral forces between the muscle fibers and communicating via the intra-and extracellular environment (Lowe et al., 2006). Its absence is characterized by progressive degeneration and weakness of the skeletal muscles, and an inability to properly repair the muscular tissue, which is gradually replaced by fat and connective tissue (Whitehead et al., 2006).

DMD is usually diagnosed between 2 and 5 years old (Balaban et al., 2005), being inexorably fatal, and the patients usually die around the second decade of life due to impairment of the cardiac and diaphragm muscle (Judge et al., 2005; Whitehead et al., 2006).Duchenne muscular dystrophy is characterized in MDX mice (an animal model for the study of Duchenne Muscular Dystrophy) by a set of muscle degeneration fibers with intense infiltrate inflammation (Nonaka, 1998). The MDX mice myonecrosis is often preceded by a collapse and detachment of the basal lamina of the sarcolemma, and subsequent muscle fiber degeneration associated with an extensive inflammatory process. Macrophages, CD4 + and CD8 + T cells represent the main constituents of the population of inflammatory cells that surround the myofiber degeneration process (Mcdowall et al., 1990; Spencer et al., 2001). Concerning this aspect, Lagrota-Candido et al. (2002) revealed that during the process of muscle degeneration, there is an accumulation of CD4 + and CD8 cells in the skeletal muscles of 4-week old MDX mice. Moreover, during the period of muscle regeneration, there is a proliferation of B lymphocytes and secretion of IFN- $\beta$ by lymphocytes. 


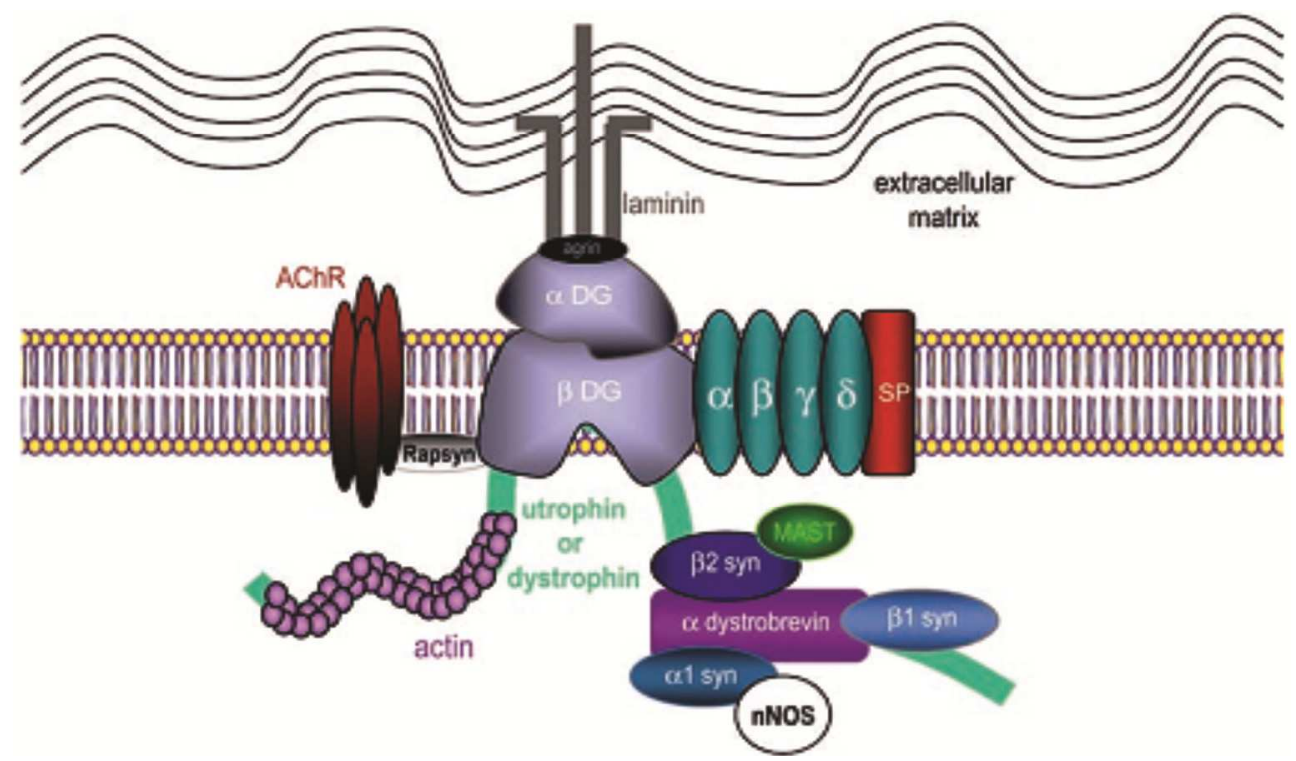

Fig. 1. Composition and schematic organization of the dystrophin glycoprotein complex (DGC) at the neuromuscular junction. Dystrophin or utrophin bind to actin filaments via their $\mathbf{N}$ terminus. At the $\mathrm{C}$ terminus, dystrophin or utrophin are associated with integral and peripheral membrane proteins that can be classified as the dystroglycan complex, the sarcoglycan-sarcospan complex and the cytoplasmic complex. Role of dystrophin and utrophin for assembly and function of the dystrophin glycoprotein complex in non-muscle tissue - review from Cellular and Molecular Life Sciences; 63 (2006) 1614-1631.

Currently, much is known about the muscle involvement during the course of DMD, but few studies have focused on the effects on the CNS, specifically in the microenvironment of the spinal motoneurons. It is known that during the course of the disease, axonal terminals enter a cycle of denervation (retraction) and reinnervation (sprouting), and this cycle can pass in a retrograde manner to the cell bodies of the spinal alpha-motoneurons. After an injury resulting in disruption of the contact between the motoneurons and their target muscle fibers, a series of changes occurs in the cell body of the neuron (for example, the presence of edema in the cell body, displacement of the nucleus to the periphery of the cell body and a decrease in electron density along with the dissolution of Nissl corpuscles), which, together, is called chromatolysis (Romanes, 1946; Lieberman, 1971; Aldskogius \& Svensson, 1993) - Figure 2.

Pastoret \& Sebille (1994) investigated the cycles of muscle degeneration and regeneration as from the second week and up to 104 weeks of life in MDX mice. Their results showed that in the second week of life, some abnormalities could be found in muscle fibers of the tibialis anterior, extensor digitorum longus, muscle longus plantar and soleus muscle. These changes included small scattered foci of degenerated muscle fibers surrounded by cellular infiltrates, "pale" muscle fibers and small groups of regenerated muscle fibers with a central nucleus. By the third week of life these abnormalities were evident and widespread in all the 

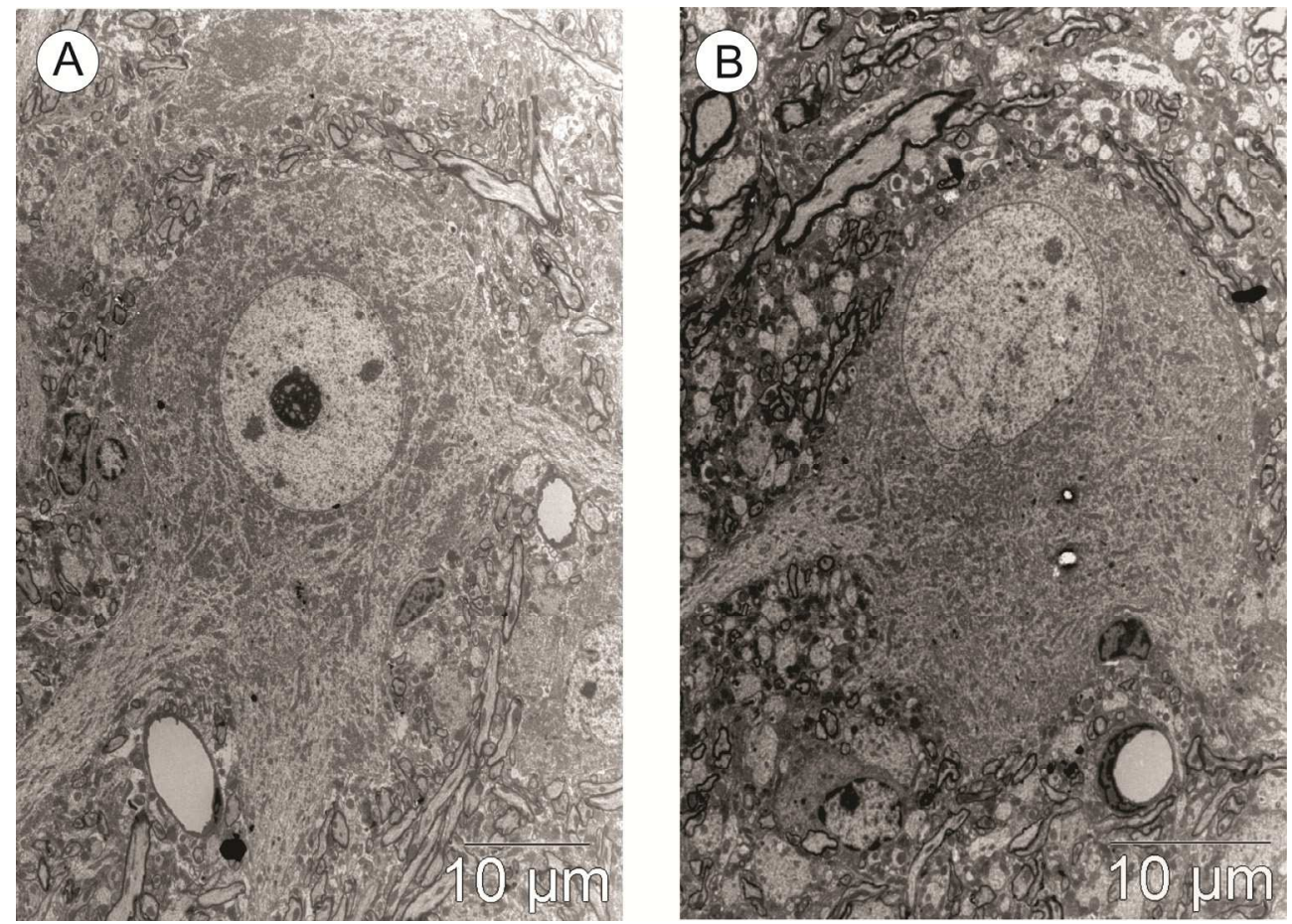

Fig. 2. B and C respectively, a motoneuron subjected to peripheral axotomy and a normal motoneuron, both observed under transmission electron microscopy. Scale $=10 \mu \mathrm{m}$. (Expression of class I major histocompatibility complex (MHC I) in the central nervous system: role in synaptic plasticity and regeneration - review from Coluna/Columna. 2010; 9(2):193-198).

muscles studied by these authors. These same authors showed that in the sixth week of life, about $50 \%$ of the muscle fibers of the lower limb muscles presented a central nucleus, and by the eighth week of life, all the muscles showed hypertrophic fibers coexisting with foci of small fibers in various stages of maturation, providing an increase in the variety of fiber diameters. Huard et al. (1992) demonstrated the expression of dystrophin in the cerebellum, cerebral cortex, hippocampus and spinal cord of the central nervous system (CNS) of humans and monkeys. However, Lidove et al. (1993) demonstrated that in mice, dystrophin is expressed almost exclusively in the pyramidal cells and in other neurons of the cerebral cortex and in the Purkinje cells. Sbriccoli et al. (1995) suggested that the dystrophin localized in the CNS has an important role in developing and maintaining the structural and functional properties in the interconnections between neurons. Evidence of abnormal connections in the adult MDX mouse brain has been demonstrated primarily by Carretta et al. (2001). Sbriccoli et al. (1995) showed that in MDX mice, there are decreased numbers of cortico-spinal tract axons. This change in the cortico-spinal tract can be justified by the role of dystrophin in the cerebral cortex, and the complete loss of its expression in MDX mice. Therefore, it plays an important role in the migration and maturation of neurons in the cerebral cortex. 
Bearing in mind the possible repercussions of the process of muscle degeneration and regeneration in the spinal microenvironment, unilateral axotomy of the sciatic nerve followed by analysis of the spinal motoneurons was used in MDX mice (Figure 3). This experimental model of peripheral nerve injury was chosen, keeping in mind that the transection of a peripheral nerve, such as the sciatic nerve, is a well-established experimental model to study the correlation between glial reactivity and neuronal response to injury at the anterior column level of the spinal cord (Lundberg et al., 2001). This is due to the fact that in this model, the only elements directly affected by the injury are the axons of spinal neurons. Thus any changes observed in the vicinity of motoneuron bodies, including reactive astrogliosis and the activation of MHC I molecules (histocompatibility complex type I), are reflections of direct communication between the neuron and the glia.
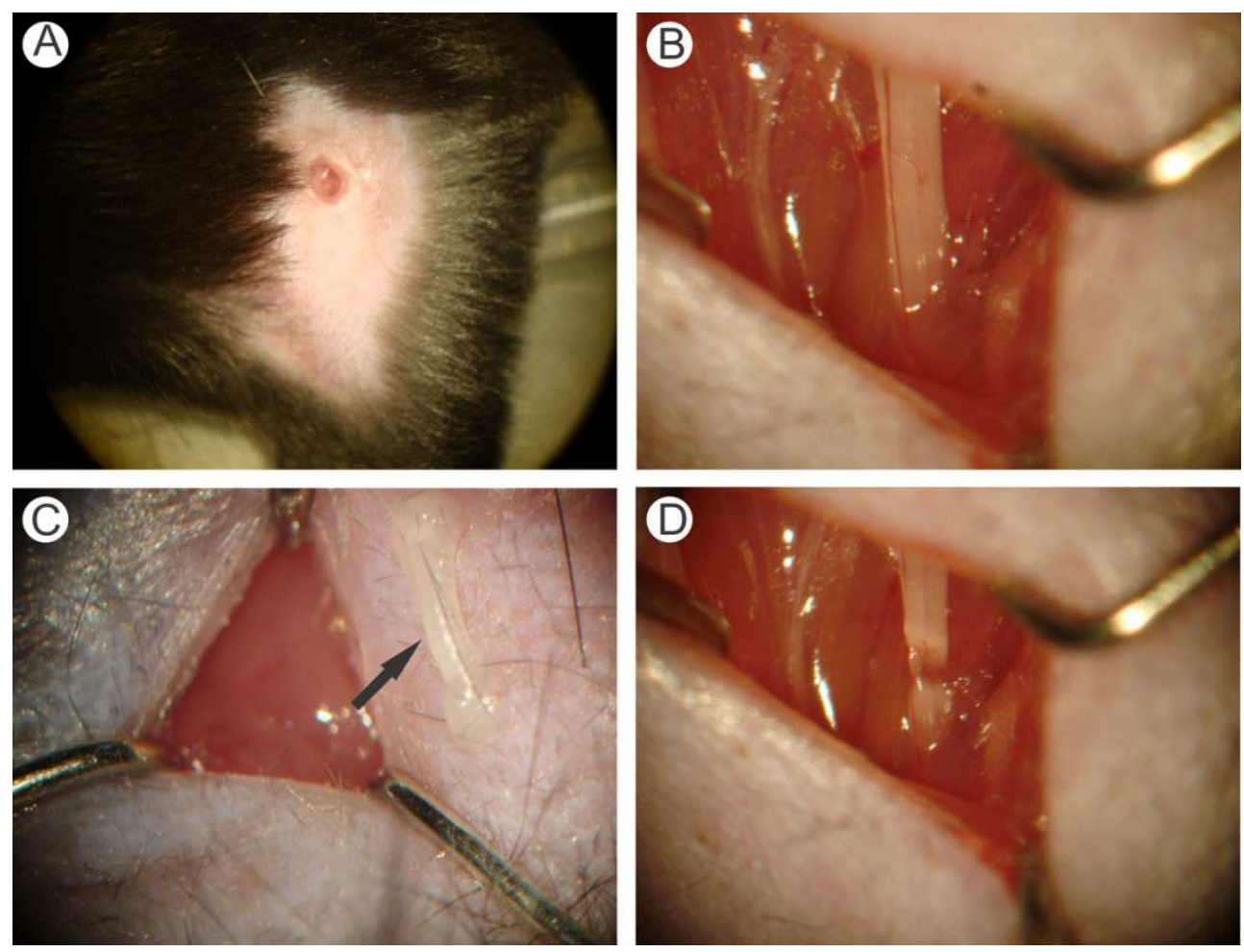

Fig. 3. A - Shaving in the region of the posterior left thigh and an incision in the skin of the mid-thigh, and then parallel to the femur using a scalpel. B - The skin and thigh muscle were carefully retracted, exposing the sciatic nerve to be transected. C - Figure showing the transected sciatic nerve. D - Crushed sciatic nerve.

Distal axotomy also induces, in addition to astroglial activation, the retraction of presynaptic terminals in contact with the cell body (Figure 4) and dendrites of the spinal alphamotoneurons (Brännström \& Kellerth, 1998: Aldskogious et al., 1999). This retraction is more intense in the synaptic terminals of the motoneuron cell body (Brännström \& Kellerth, 1998), and occurs in the acute phase of injury, being influenced by the change in physiological state 
of the neurons, that pass from the transmission state condition to the survival and regeneration condition (Piehl et al., 1998). Reier et al. (1989) have proposed that the astrocytes act as a barrier to axon growth by way of the formation of scar tissue, but may promote its regeneration by releasing neurotrophic factors (Baba, 1998). Therefore the astrocytes directly influence the dynamics of synaptic contacts (Walz, 1989: Araque \& Perea, 2004) and may thus influence the processes of synaptic reorganization after injury (Aldskogius et al., 1999).

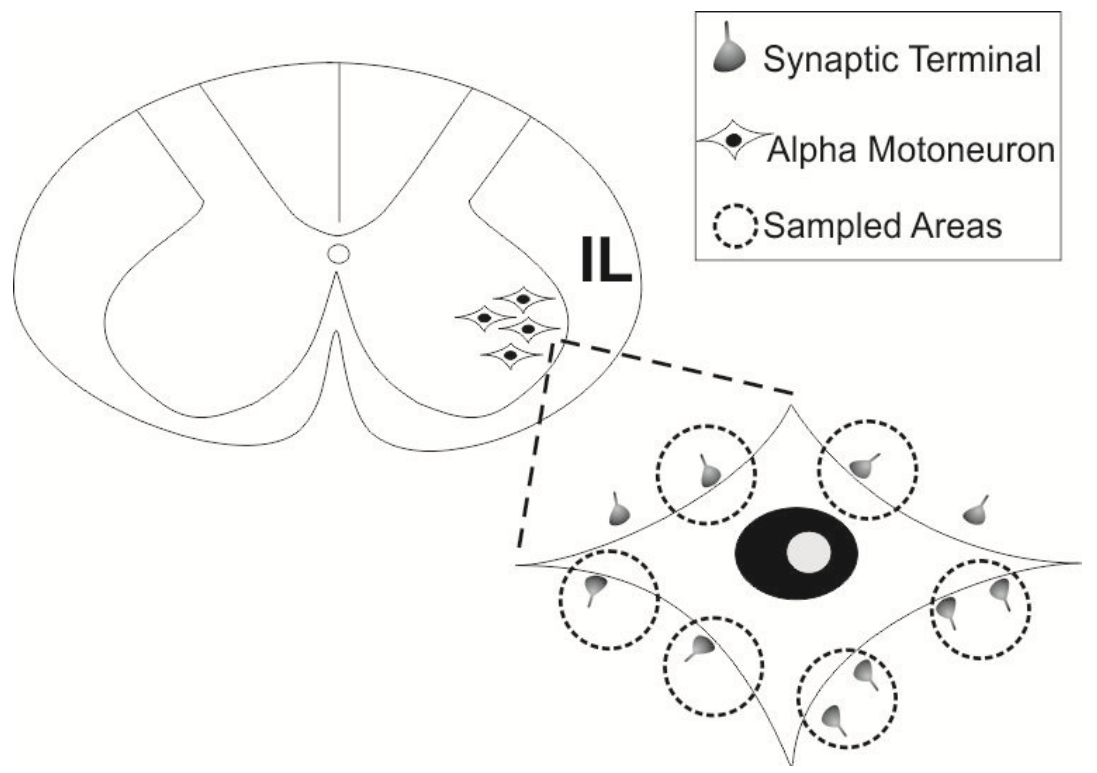

Fig. 4. Schematic representation of the sciatic nerve pool in the ventral horn of the spinal cord. One motoneuron is shown in detail with apposed presynaptic terminals. The dashed circles represent the areas where synaptic retraction is present. 2010 Blackwell Publishing Ltd, Neuropathology and Applied Neurobiology, 36 , 55-70.

\section{Results and discussion}

The immunohistochemistry and transmission electron microscopy results demonstrated that glial reactivity varies between the two strains. In MDX mice with no injury, an increase in GFAP immunoreactivity can be seen as compared to the same group in C57BL/10 mice (Figure 5A and 5B, respectively). The MDX and C57BL/10 ipsilateral groups showed a significant increase in reactive astrogliosis (GFAP) in relation to the contralateral groups in both strains (Figures 5E and 5F, respectively). However, with respect to this, there was evidence of increased astrocyte activity in the MDX contralateral group, as demonstrated by astrogliosis in the region of the spinal alpha-motoneurons (Figure 5D). This increase was approximately $49.5 \%$ higher than in the same side of the C57BL/10 strain. The analysis showed a significant increase in ipsilateral activity of the astrocytes in MDX mice, about $65.2 \%$ higher as compared to the C57BL/10 mice. Increased astrogliosis at the level of the anterior column of the spinal cord correlates with significant synaptic plasticity in the process of regeneration of injured neurons, as demonstrated by Emirandetti et al. (2006). 
However, when the ipsi/contralateral ratio of the GFAP expression was analyzed, it was confirmed that there was no significant difference between the strains studied.

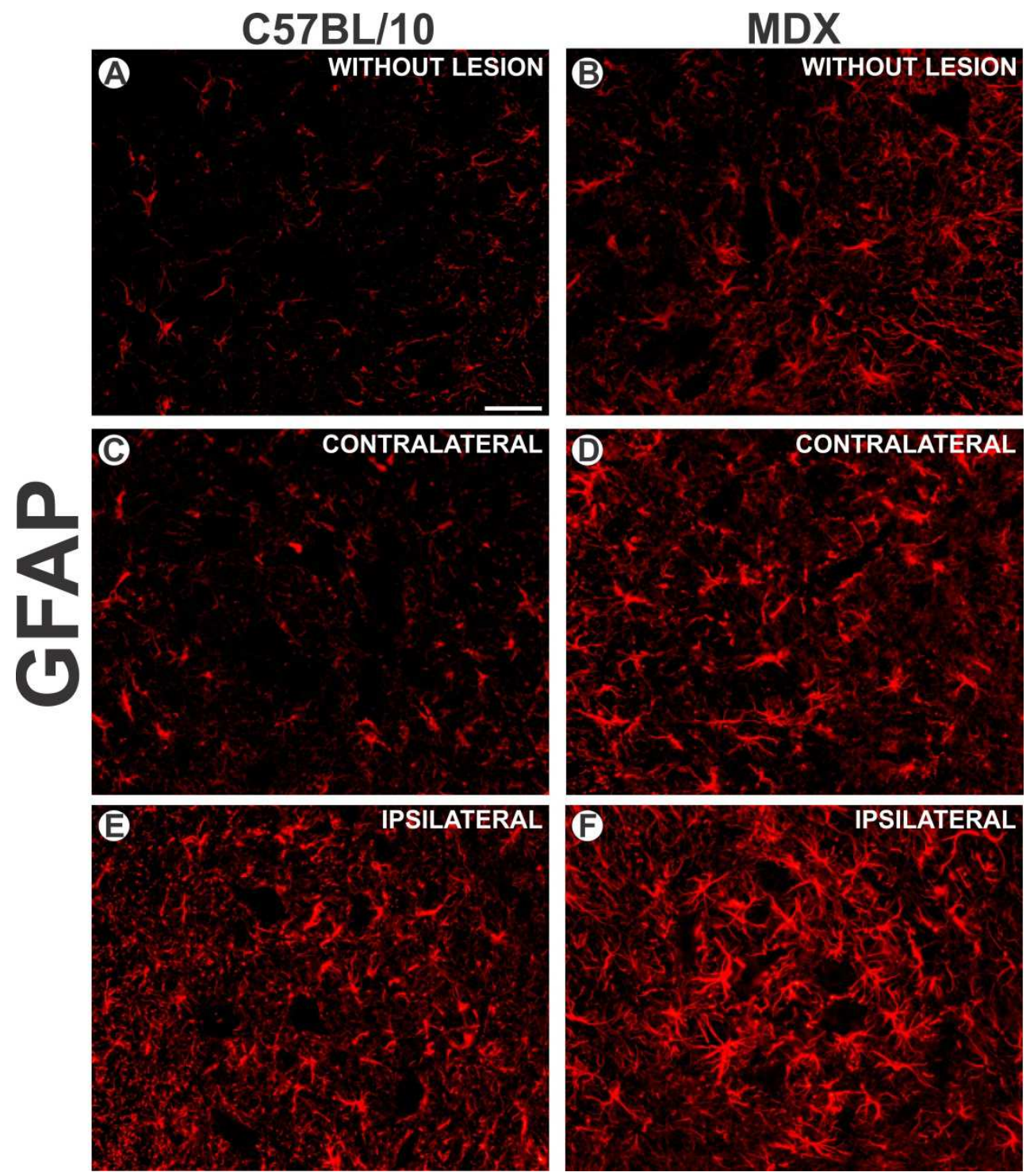

Fig. 5. Anti-GFAP immunostaining. A and B show non-injured animals (C57BL/10 and MDX, respectively). $C$ and D show contralateral groups seven days after axotomy (C57BL/10 and MDX, respectively). E and F show ipsilateral sides, seven days after axotomy (C57BL/10 and MDX, respectively). Note that in general there is a greater expression of GFAP in the MDX strain in relation to the C57BL/10 strain. 2010 Blackwell Publishing Ltd, Neuropathology and Applied Neurobiology, 36 , 55-70. 
Synaptic Changes at the Spinal Cord Level

C57BL/10
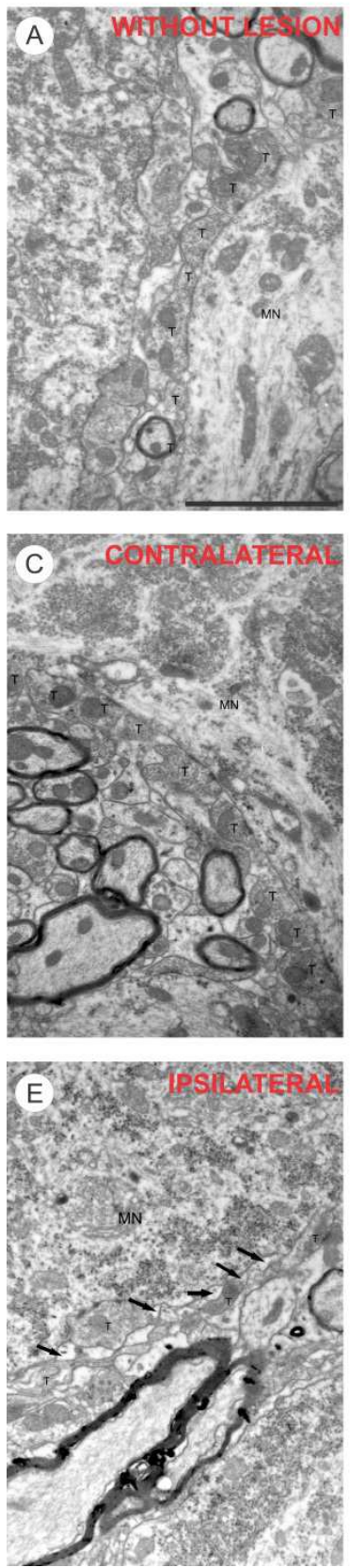

MDX
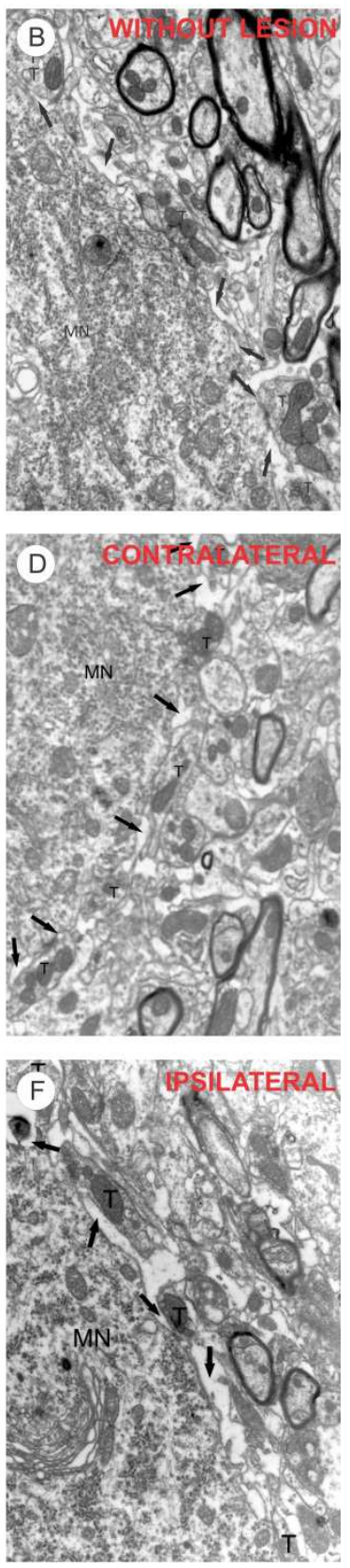

Fig. 6. Ultrastructure of the surface of without lesion spinal cord alpha motoneurons (MN). A - C57BL/10; B - MDX. Observe the normal C57BL/10 terminal apposition on the 
postsynaptic membrane. In contrast, the MDX inputs (presynaptic terminals - T) to the motoneurons are partially detached (arrows), with a reduced area of apposition. C - Synaptic covering in the C57BL/10 contralateral side one week after axotomy. E - Synaptic elimination following axotomy in C57BL/10 mice. The arrows represent astroglial processes and $\mathrm{T}$ represents the synaptic boutons. D - Synaptic covering in the MDX contralateral side. F Synaptic elimination following axotomy in MDX mice. The arrows represent astroglial processes and $\mathrm{T}$ represents the synaptic boutons. Observe a more intense synaptic loss in MDX mice, also present on without lesion at the contralateral side of the lesion, indicating that the course of the disease had an impact on the spinal cord circuits. Scale $=2 \mu \mathrm{m}$. 2010 Blackwell Publishing Ltd, Neuropathology and Applied Neurobiology, 36 , 55-70.

Although there was no statistical difference between the ipsi/contralateral ratios of the two strains, it is evident that the MDX mice present a greater astrocyte response in relation to the C57BL/10 mice, taking into account the difference in astrogliosis between the ipsilateral and contralateral sides of each strain. The fact that the MDX mice showed a superior basal level of GFAP in relation to the C57/BL10 mice, suggests that the effects of Ducehnne Muscular Dystrophy are directly reflected in the spinal cord microenvironment, resulting in significant changes in the spinal circuits. It is suggested that such changes in the MDX mice contribute to the progress of the disease by affecting the functionality of the motoneurons.

An ultrastructural analysis of the alpha-motoneurons plasma membrane showed the presence of synaptic elimination processes in both sides (injured and uninjured) on MDX mice. In the ipsilateral side, the two strains exhibited significant synaptic retraction, and the MDX mice showed less synaptic elimination when evaluating the percentage of synaptic covering before and after axotomy (MDX - 14.61\% and C57/BL10 - $23.60 \%$ approximately, Figure $6 \mathrm{E}$ and $6 \mathrm{~F}$ ). This fact demonstrates that in addition to the synaptic elimination resulting from the disease, the MDX mice probably have a lower potential for response to peripheral nerve injury. This may be related to the fact that these animals show a lower expression of MHC I (Simões \& Oliveira, 2009).

These results show a correlation between glial reactivity, subsequent to the axotomy process, and the synaptic retraction that occurs at the spinal cord (Emirandetti et al., 2006), more evident in the MDX strain.

The communication between neurons and glia through MHC I signaling, probably involves receptors that may be able to translate the signal from MHC I to the neurons, and also from the astrocytes and microglia. In an attempt to understand the functional role of MHC I molecules in the CNS, specifically in synaptic plasticity and the regeneration of neurons in adult animals, Oliveira et al. (2004), performed sciatic nerve transection in knock out mice for the $\beta 2$ microglobulin protein expression, a subunit of the complex of MHC I. In this study, these authors demonstrated that MHC I plays an important role in maintaining selective inhibitory terminals in apposition to axotomized neurons (Figure 8).

The absence or lower expression of MHC I results in a minor retraction of presynaptic boutons thus reducing the regenerative potential of injured neurons (Oliveira et al., 2004). This fact is consistent with that shown in MDX mice, keeping in view the relative synaptic elimination after axotomy. Similarly, Sabha et al. (2008) showed that the lower expression of 

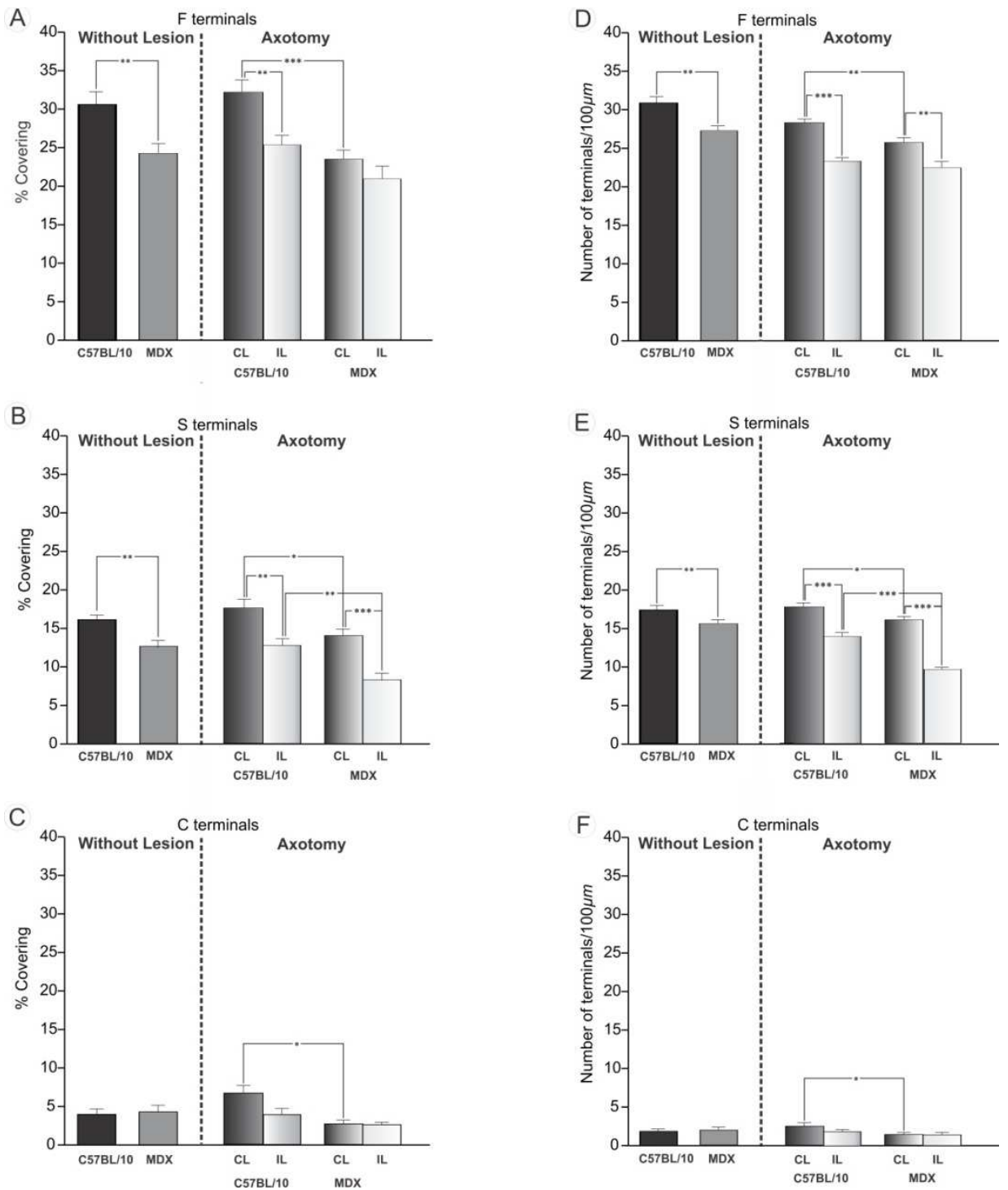

Fig. 7. Representation of the quantitative ultrastructural analysis of the percentage of covering by $\mathrm{F}, \mathrm{S}$ and $\mathrm{C}$ synaptic terminals, and the quantitative ultrastructural analysis of the number of terminals $(\mathrm{F}, \mathrm{S}$ and $\mathrm{C})$ in apposition $/ 100 \mu \mathrm{m}$. A, B and C - show the covering of the F, S and C terminals as a percentage, for, respectively, those without injury and the contralateral and axotomized sides of both strains. D, E and F - show the number of presynaptic F, S and C terminals, respectively, in apposition to the neuronal membrane/100 $\mu \mathrm{m}$, for those without injury, and for the control and axotomized groups of both strains. Note that in the MDX mice, the $\mathrm{F}$ and $\mathrm{S}$ terminals are reduced before and after axotomy in both groups. 2010 Blackwell Publishing Ltd, Neuropathology and Applied Neurobiology, 36 , 55-70. 
MHC I in C57/BL6J mice results in lower regenerative capacity in relation to $\mathrm{A} / \mathrm{J}$ mice, which showed a higher expression of MHC I. Thus one can suggest that MDX mice show a lower potential axonal regeneration after peripheral nerve injuries, reflecting the evolution of the disease associated with a lower capacity to express MHC I (Figure 9).

Normal synaptic covering
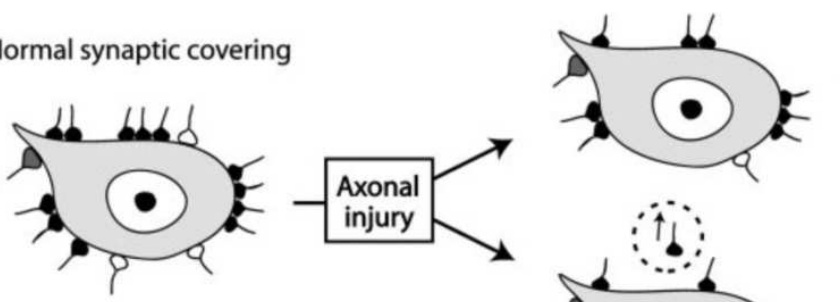

Presence of MHC-1
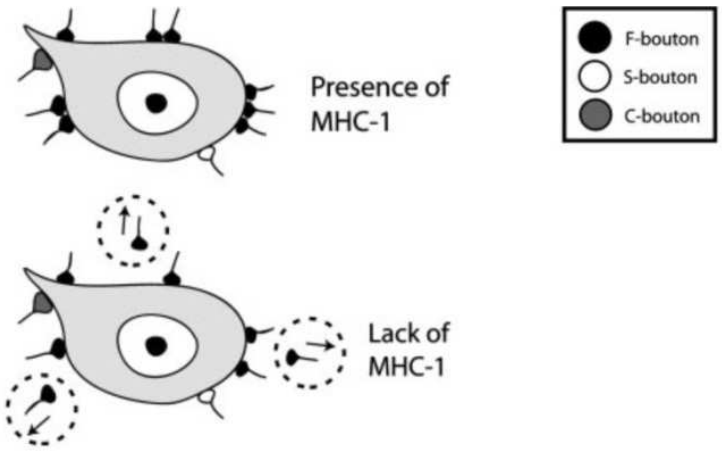

Fig. 8. Scheme showing the synaptic retraction process in motoneurons with the presence and absence of MHC-I. Note the retraction of the boutons in the motoneuron with the absence of MHC-I as compared to the motoneuron with MHC-I. Oliveira et al., PNAS, 101(51): 17843-17848, 2004.

This hypothesis was tested by the sciatic nerve crush, another type of peripheral nerve injury, followed by an analysis of motor recovery using the walking track test (Figure 10). After crushing, the animals were monitored for three weeks, every day up to the tenth day after injury, and then on alternate days from the eleventh to the twenty-first day after injury. The results show that MDX mice have a motor deficit compared with C57BL/10 mice, even before injury (MDX, $-35.14 \pm 3.82$, mean + SD; C57BL/10, $-7.63 \pm 0.94, p<0.001$ ). The motor recovery curve was similar for the two strains, but the MDX mice showed a significant reduction in motor function after three weeks (MDX, -27.76 \pm 5.03 ; C57BL/10, $-7.71 \pm 2.99$, $\mathrm{p}$ $<0.01)$.

With regard to synaptic immunoreactivity, a study of the expression of synaptophysin showed there was reduced immunoreactivity in the MDX strain, both ipsilateral and contralateral to the lesion (Figure 13). A significant decrease in the expression of synaptophysin was observed in the MDX mice contralateral to the lesion, approximately $27 \%$ lower as compared to the same side in the C57BL/10 strain.

The immunohistochemical evaluation showed an increase in immunoreactivity for the neurofilaments (Figure 11) and the p75 NTR - low affinity receptor for neurotrophins (Figure 12) in both strains after crushing. It can also be seen that the MDX mice showed an increased expression of the neurofilament and p75NTR contralateral to the lesion. Similarly, immunostaining showed a better reorganization of regenerated fibers in the C57BL/10 mice. These results suggest that the reduction in motor function in the MDX mice could be related to the cycles of muscle degeneration that directly affect the neuromuscular junctions. 


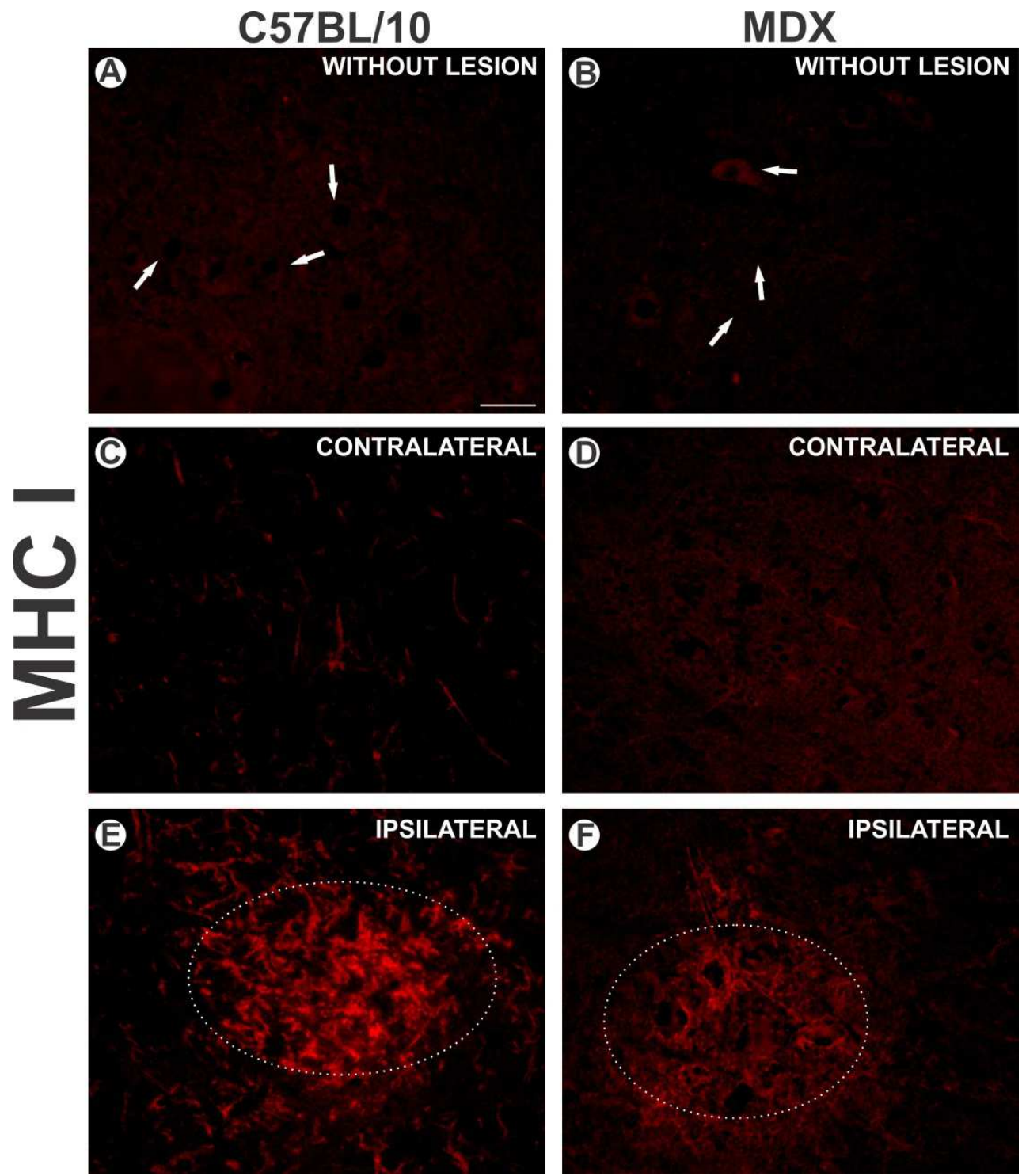

Fig. 9. A and B - Major histocompatibility complex of class I (MHC I) expression in noninjured C57BL/10 and MDX mice, respectively. C and D - Immunolabeling against the MHC I complex on the contralateral (CL) (non-injured) side of the spinal cord. Note the low basal expression of MHC I in both strains. E and F - Immunolabeling against the MHC I protein complex on the ipsilateral (IL) side of the spinal cord 1 week after axotomy, showing an increased expression in both strains, especially in the motoneuron surroundings and adjacent neuropil (dashed areas). The arrows indicate the cell body of the motoneurons. Scale $=50 \mathrm{~mm}$. 2010 Blackwell Publishing Ltd, 9 Neuropathology and Applied Neurobiology, 36 , 55-70. 10 
Trainning days

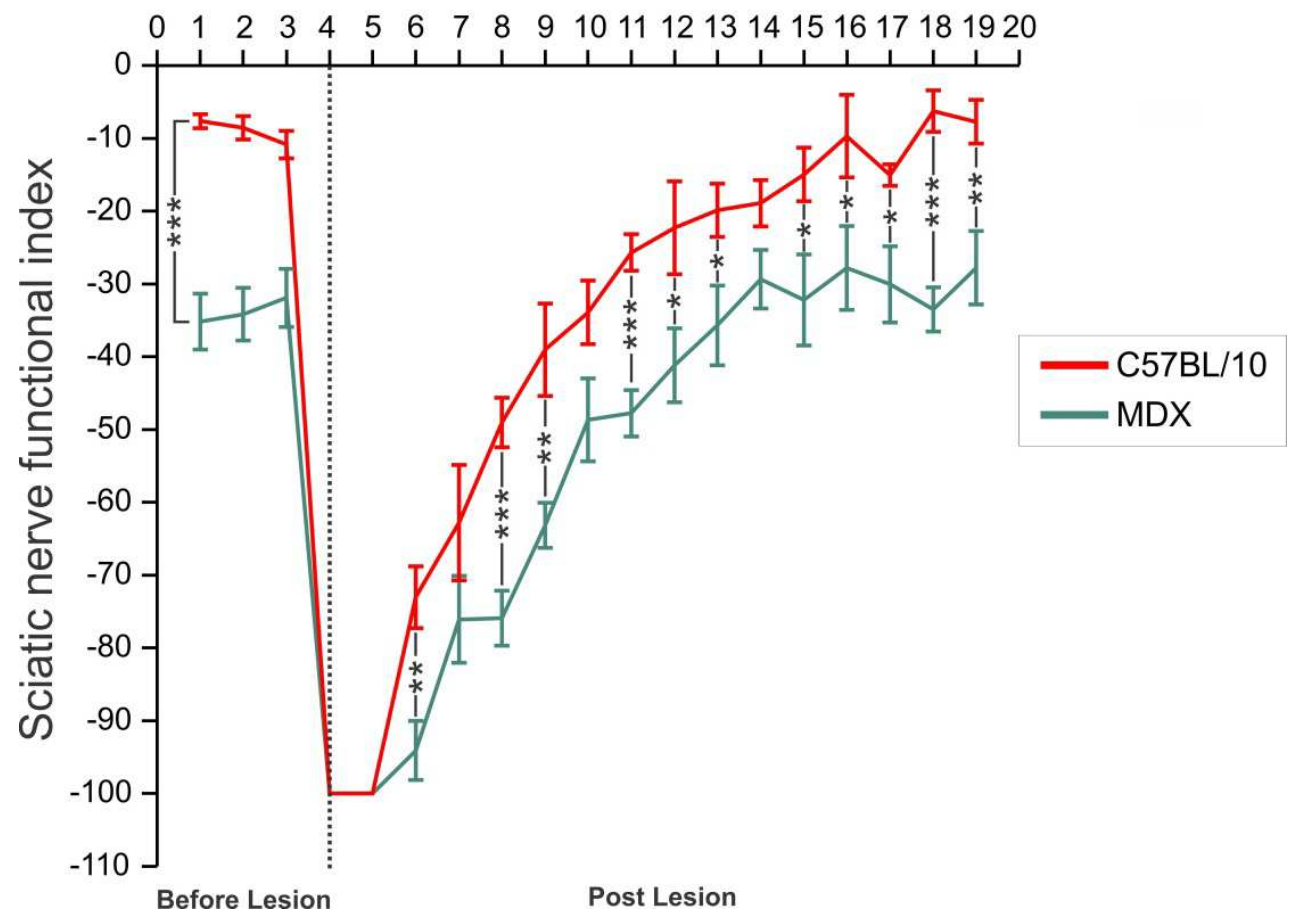

Fig. 10. Graph showing the motor function recovery of the two strains. Note that the MDX mice showed weakened motor function in relation to the C57BL/10 mice, both before and after the sciatic nerve crush. 
Synaptic Changes at the Spinal Cord Level

and Peripheral Nerve Regeneration During the Course of Muscular Dystrophy in MDX Mice

C57BL/10
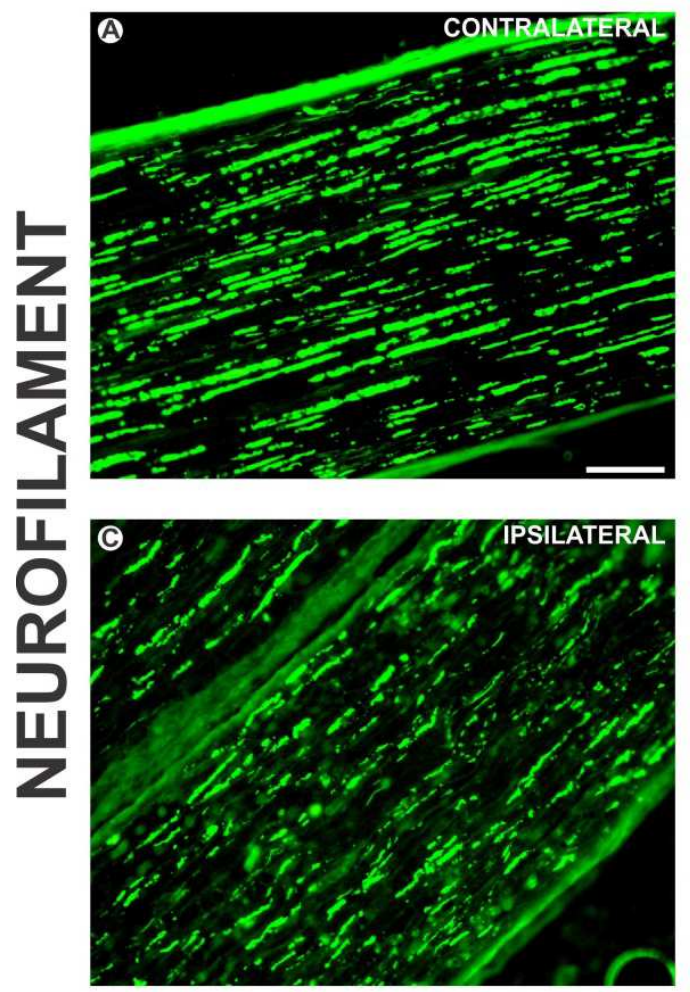

MDX
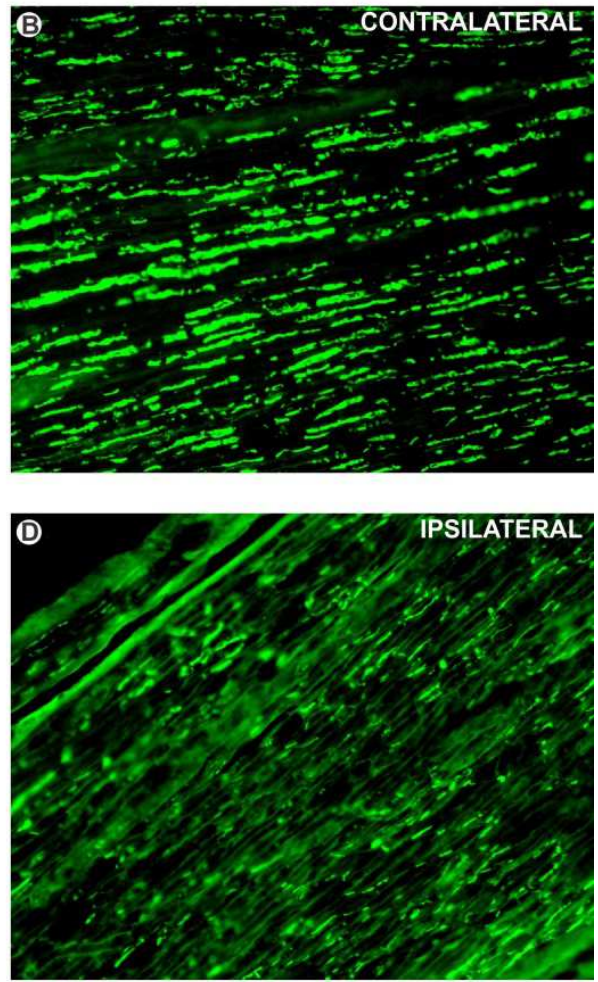

Fig. 11. Anti-neurofilament immunostaining three weeks after the sciatic nerve crush. A and $\mathrm{B}$ show the contralateral nerve. $\mathrm{C}$ and $\mathrm{D}$ show the ipsilateral nerve. Note that there is better organization in the axon fibers after nerve crush in the C57BL/10 mice as compared to the MDX strain. 
C57BL/10

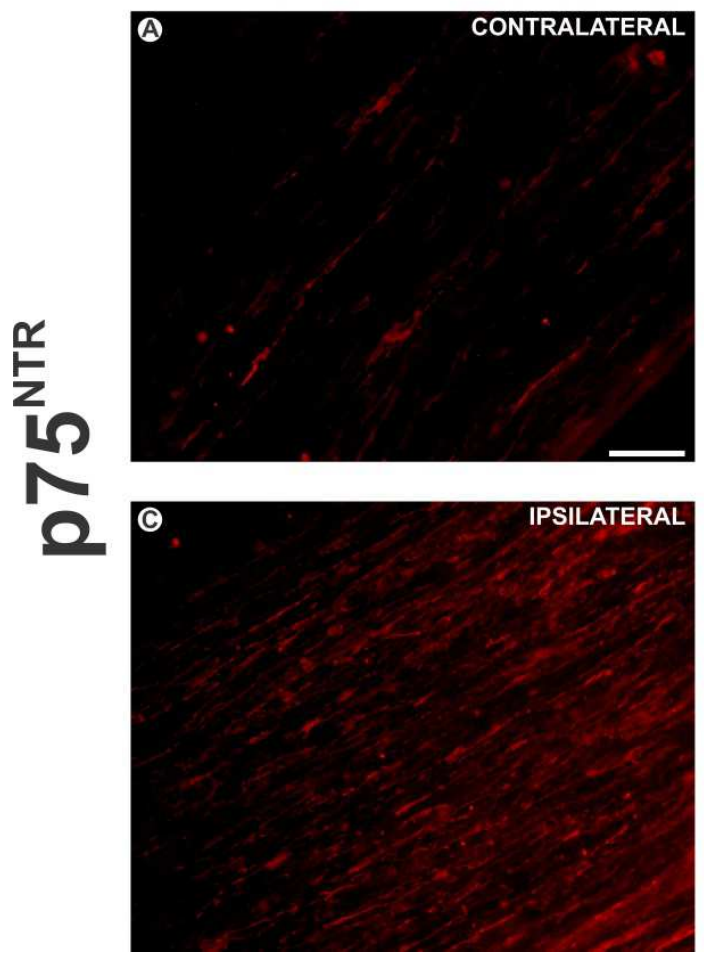

MDX
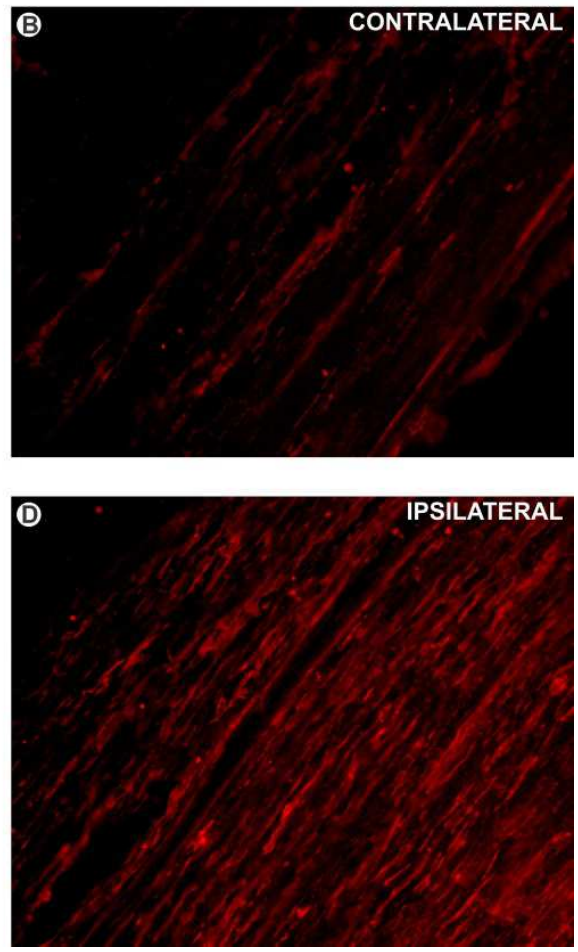

Fig. 12. Immunostaining of the anti- p75NTR (low affinity receptor for neurotrophins) three weeks after sciatic nerve crush. A and B show the contralateral nerves in both strains. $\mathrm{C}$ and $\mathrm{D}$ show the ipsilateral nerves. Note that there is greater immunoreactivity in the MDX mice as compared to the C57BL/10 mice before and after nerve crushing. 


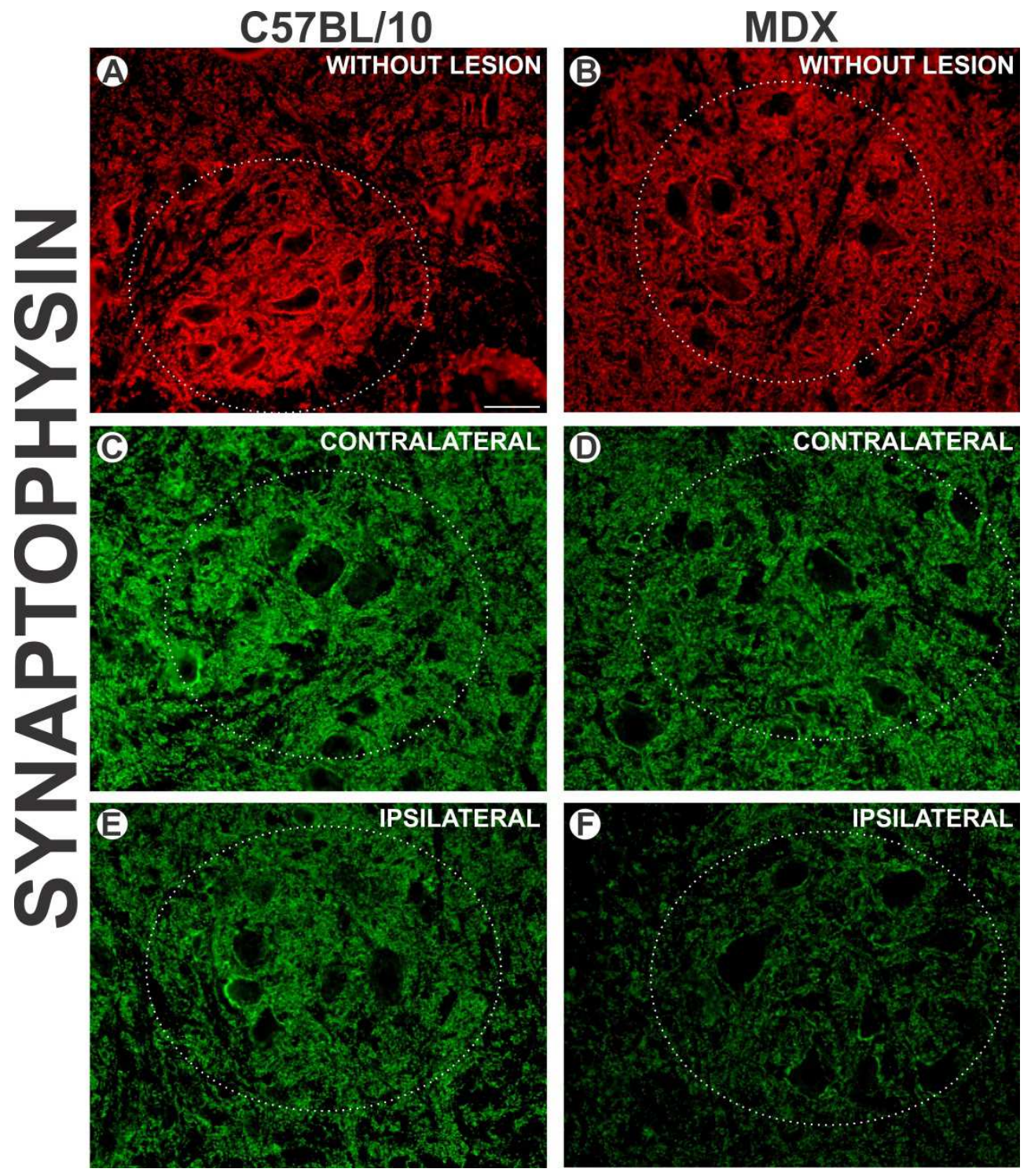

Fig. 13. A and B - Synaptophysin Immunolabeling in non-injured animals. C and D Synaptophysin immunolabelling of the spinal cord contralateral to the injury 1 week after axotomy. Note the lower synaptic covering in the MDX mice. E and F - the lumbar spinal cord ispsilateral to the injury, 1 week after axotomy, showing an overall decrease in synaptophysin expression around the axotomized motor neuron. The areas containing axotomized motor neurones are highlighted by dashed circles. Scale $=50 \mathrm{~mm} .2010$ Blackwell Publishing Ltd, Neuropathology and Applied Neurobiology, 36 , 55-70. 
Altogether, the results described herein indicate that the reduction of inputs in the spinal alpha-motoneurons resulted from a partial disconnection between the motoneuron axon and the muscle targeted during the cycles of muscle degeneration and regeneration that occurred after the second week postnatal. It should be noted that when the animals underwent axotomy at six weeks old, there was a clear central nucleus (indicative of regeneration) in approximately $50 \%$ of the muscle fibers (Pastoret \& Sebille, 1994). Moreover, in the MDX mice there was a decrease in the number of cells in the cortico-spinal tract (Sbriccoli et al., 1995) and this could also reduce the number of inputs to the spinal alpha-motoneurons and thus cause a decrease in synaptic covering. The present results showing a decrease in protein expression of the synaptophysin and synaptic covering when compared with the findings of Oliveira et al. (2004), are consistent with the idea that the MHC I acts on the stability of the synaptic terminals. Nevertheless, considering its role in signaling between the presynaptic terminals and the motoneurons, as well as taking part in the communication of these with the glia, the greater expression of this protein in the C57BL/10 mice could promote a greater nerve regeneration process as compared to the MDX mice.

As demonstrated by Oliveira et al. (2004), after a nerve injury, MHC I plays a key role in stabilizing the selective inhibitory synapses, which contributes to the presynaptic terminal retraction process occurring in a specific way. Sabha et al. (2008) correlated an increased expression of MHC I with an intensification of the synaptic elimination process seven days after peripheral axotomy in the spinal cord microenvironment. This was evident in both C57BL/10 and MDX strains, but with a lower expression of MHC I in the MDX mice. One hypothesis for this occurrence is that the muscle degeneration and regeneration process already proceeding in these mice at a young age (Pastoret \& Sebille, 1994), promotes a "partial disconnection" of the sciatic nerve with its target muscle, possibly stimulating an increased expression of MHC I molecules in these animals. This fact may contribute to the differentiated response of the MDX mice in comparison with that normally seen in the C57BL/10mice, similarly to what was shown in the work of Sabha et al. (2008), where the MHC I expression remained high over a period of up to 3 weeks after axotomy. Thus it is suggested that the lower expression of MHC I in MDX mice may indicate a reduced capacity for adjustment of the inputs by the motoneurons, indicating a lower regenerative potential after nerve injury.

\section{References}

Aldskogius, H. \& Svensson, M. 1993. Neuronal and glial responses to axon injury. In S.K. Malhotra (eds): Advances in structural biology. Greenwich, Connecticut: JAI Press.

Aldskogius, H.; Liu, L.; Svensson, M, 1999. Glial responses to synaptic damage and plasticity. Journal Neuroscience Research, 58:33-41.

Arahata, K.: Ishihara, T.; Nonaka, I.; Ozawa, E.; Sugita, H. 1988. Imunnostaining of skeletal and cardiac muscle surface membrane with antibody against Duchenne muscular dystrophy peptide. Nature, 333:861-868.

Araque, A. \& Perea, G. 2004. Glial modulation of synaptic transmission in culture. Glia. 47:241-248.

Baba, A. 1998. Role of endothelin B receptor signals in reactive astrocytes. Life Sci., 62 (17/18):1711-1715. 
Balaban, B.; Matthews DJ.; Clayton, GH.; Carry T. 2005. Corticosteroid treatment an functional improvement in Duchenne Muscular Dystrophy: long-term effect. Am J Phys Med Rehabil., 84:843-850.

Brännström, T. \& Kellerth, J.O. 1998. Changes in synaptology of adult cat spinal alphamotoneurons after axotomy. Experimental Brain Research, 118:1-13.

Carreta, D.; Santarelli, M.; Vanni, D.; Carrai, R.; Sbriccoli, A.; Pinto, F.; Minciacchi, D. 2001 The organization of spinal projecting brainstem neurons in an animal modelo $f$ muscular dystrophy: A retrograde tracinig study on mdx mutante mice. Brain Research, 895:213-222.

Chelly, J.; Kaplan, J.C.; Maire, P.; Gautron, S.; Kahn, A. 1988. Transcription of the dystrophy $(m d x)$ in the mouse. Proc. Natl. Acad. Sci. USA, 81:1189-1192.

Emirandetti, A.; Zanon, R.G.; Sabha, M.J.; Oliveira, A.L.R. 2006. Astrocyte reactivity influences the number of presynaptic terminals apposed to spinal motoneurons after axotomy. Brain Research, 1095:35-42.

Haenggi T. \& Fritschy J.M. 2006. Role of dystrophin and utrophin for assembly and function of the dystrophin glycoprotein complex in non-muscle tissue. Cell Mol Life Sci. 2006 Jul;63(14):1614-31.

Huard, J.; Coté, P.Y.; Parent, A.; Bouchard, J.P.; Tremblay, J.P. 1992. Dystrophin-like immunoreactivity in monkey and human brain areas involved in learning and motor functions. Neuroscience Lett., 141:181-186.

Judge, L.M.; Haraguchi, M.; Chamberlain, J.S. 2005. Dissecting the signaling and mechanical functions of the dystrophin-glycoprotein complex. Journal of Cell Science., 119:1537-1546.

Lagrota-Candido, J.; Vasconcellos, R.; Cavalcanti, M.; Bozza, M.; Savino, W.; Quirico-Santos, T. 2002. Resolution of skeletal muscle inflammation in $m d x$ dystrophic mouse is accompanied by increased immunoglobulin and interferon-gama production. Int. J. Exp. Path., 83:121-132.

Lidov, H.G.; Byers, T.J.; Kunkel, L.M. 1993. The distribuition of dystrphin in the murine central nervous system: an immunocytochemical study. Neuroscience, 54:167-187.

Lieberman, A. R. 1971. The axon reaction: a review of the principal features of perikaryal responses to axon injury. Int. Rev. Neurobiol., 14:49-124.

Lindå, H.; Piehl, F.; Dagerlind, A.; Verge, V. M.; Arvidsson, U.; Cullheim, S.; Risling, M.; Ulfhake, B.; Hokfelt, T. 1992. Expression of GAP-43 mRNA in the adult mammalian spinal cord under normal conditions and after different types of lesions, with special reference to motoneurons. Exp. Brain Res. 91, 284-295.

Lindå, H.; Hammarberg, H.; Cullheim, S.; Levinovitz, A.; Khademi, M.; Olsson, T. 1998. Expression of MHC class I and $\beta 2$ - Microglobulin in rat spinal motoneurons: regulatory influences by IFN - gamma and axotomy. Exp. Neurol., 150, 282-295.

Lowe, Dawn A.; Willians, Brian O.; Thomas, David D. and Grange, Robert. 2006. Molecular and cellular contractile dysfunction of dystrophic muscle from young mice. Muscle \& Nerve., 34:92-100.

Lundberg, C.; Lidman, O.; Holmdahl, R; Olsson, T; Piehl, F.2001. Neurodegeneration and glial activation patterns after mechanical nerve injury are differentially regulated by non-MHC genes in congenic inbred rat strains. J Comp Neurol., 26;431(1):75-87.

Mcdowall, R.M.; Dunn, M.J.; Billiau, A. 1990. Nature of the mononuclear infiltrate and the mechanism of muscle damage in juvenile dermatomyositis and Duchenne muscular dystrophy. J. Neurol. Science, 99:199-217.

Nonaka, I. 1998. Animals models of muscular dystrophies. Loboratory Anim. Sci. 48:8-16. 
Oliveira, A.L.; Thams, S.; Ldman, O.; Piehl, F.; Hökfelt, T.; Kärre, Lindå, H.; Cullhem, 2004. A role for MHC class I molecules in synaptic plasticity and regeneration of neurons after axotomy. PNAS. 101(51):17843-17848.

Pastoret, C. \& Sebille, A. 1994. MDX mice show progressive weakness and muscle deterioration whith age. Journal of Neurological Sciences, 129:97-105.

Pearce, J.M.S. 2005. Early Observations on Duchenne-Meryon muscular dystrophy. Eur Neurol., 54: $46-48$.

Piehl, F.; Hammarberg, H.; Hokfelt, T.; Cullheim, S. 1998. Regulatory effects of trophic factors on expression and distribuition of CGRP and GAP-43 in rat motoneurons. J. Neurosci., 5:1321-1333.

Radley, H.G.; Davies, M.J.; Grounds, M.D. 2007. Reduced muscles necrosis and long-term benefits in dystrophic mdx mice after cV1q (blockade of TNF) treatment. Neuromuscular Disorders, 18:227-238

Reier, P.J.; Eng, L.F.; Jakeman, L. 1989. Reactive astrocyte and axonal outgrowth in the injured CNS: is gliosis really an impediment to regeneration? Neur. Reg. Transpl. Front. Clinical Neuroscience, 6;193-209.

Romanes, G. 1946. Motor localization and the effects of nerve injury on the ventral horn cells of the spinal cord. J Anat., 80:117-131.

Sabha, M.JR.; Emirandetti, A.; Cullheim, S.; Oliveira, A.L.R. 2008. MHC I expression and synaptic plasticity ind different mice strains after axotomy. Synapse, 62:137-148.

Sbriccoli, A.; Santarelli, M.; Carreta, D.; Pinto, F.; Granato, A.; Minciacchi, D. 1995. Architectural changes of the cortiço-spinal system in the dystrophin defective $\mathrm{mdx}$ mice. Neuroscience Letters, 200:53-56.

Simões G.F. \& Oliveira, A.L. 2010. Alpha motoneurone input changes in dystrophic MDX mice after sciatic nerve transection. Neuropathol Appl Neurobiol., 36(1):55-70.

Spencer, M.J.; Montecino-Rodrigues, E.; Dorshkind, K.; Tidball, J.G. 2001. Helper (CD4+) and cytotoxic (CD8+) T cells promote the pathology of dystrophin-deficient muscle. Clin. Immunol., 989:235-243.

Wals, W. 1989 Role of glial cells in the regulation of the brain ion microenvironment. Prog. Neurobiol., 33(4):309-333.

Whitehead, N.P.; Yeung, E.W. and Allen, D. 2006. Muscle damage in MDX (dystrophic) mice: role of calcium and reactive oxygen species. Clinical and Experimental Pharmacology and Physiology. 33:657-662.

Zanon, R.G.; Emirandetti, A.; Simões, G.F.; Freria, C.M.; Victório, S.C.; Cartarozzi, L.P.; Barbizan, R.; Oliveira, A.L.R. 2010. Expressão do complexo de histocompatilidade principal de classe I (MHC I) no sistema nervoso central: plasticidade sináptica e regeneração. COLUNA/COLUMNA.; 9(2):193-198 


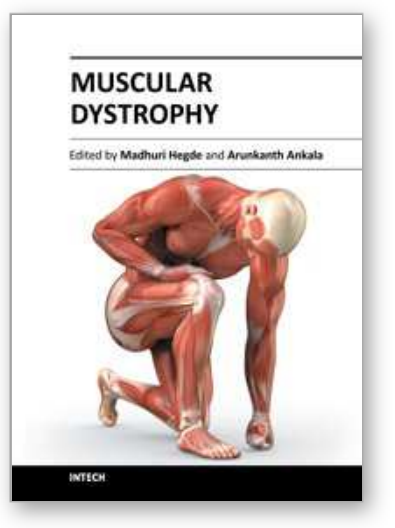

\author{
Muscular Dystrophy \\ Edited by Dr. Madhuri Hegde
}

ISBN 978-953-51-0603-6

Hard cover, 544 pages

Publisher InTech

Published online 09, May, 2012

Published in print edition May, 2012

With more than 30 different types and subtypes known and many more yet to be classified and characterized, muscular dystrophy is a highly heterogeneous group of inherited neuromuscular disorders. This book provides a comprehensive overview of the various types of muscular dystrophies, genes associated with each subtype, disease diagnosis, management as well as available treatment options. Though each different type and subtype of muscular dystrophy is associated with a different causative gene, the majority of them have overlapping clinical presentations, making molecular diagnosis inevitable for both disease diagnosis as well as patient management. This book discusses the currently available diagnostic approaches that have revolutionized clinical research. Pathophysiology of the different muscular dystrophies, multifaceted functions of the involved genes as well as efforts towards diagnosis and effective patient management, are also discussed. Adding value to the book are the included reports on ongoing studies that show a promise for future therapeutic strategies.

\title{
How to reference
}

In order to correctly reference this scholarly work, feel free to copy and paste the following:

Gustavo Ferreira Simões and Alexandre Leite Rodrigues de Oliveira (2012). Synaptic Changes at the Spinal Cord Level and Peripheral Nerve Regeneration During the Course of Muscular Dystrophy in MDX Mice, Muscular Dystrophy, Dr. Madhuri Hegde (Ed.), ISBN: 978-953-51-0603-6, InTech, Available from: http://www.intechopen.com/books/muscular-dystrophy/synaptic-changes-at-the-spinal-cord-level-andperipheral-nerve-regeneration-during-the-course-of-mus

\section{INTECH}

open science | open minds

\section{InTech Europe}

University Campus STeP Ri

Slavka Krautzeka 83/A

51000 Rijeka, Croatia

Phone: +385 (51) 770447

Fax: +385 (51) 686166

www.intechopen.com

\section{InTech China}

Unit 405, Office Block, Hotel Equatorial Shanghai

No.65, Yan An Road (West), Shanghai, 200040, China 中国上海市延安西路65号上海国际贵都大饭店办公楼 405 单元

Phone: +86-21-62489820

Fax: +86-21-62489821 
(C) 2012 The Author(s). Licensee IntechOpen. This is an open access article distributed under the terms of the Creative Commons Attribution 3.0 License, which permits unrestricted use, distribution, and reproduction in any medium, provided the original work is properly cited. 